\title{
Geståo Visual: mapeando experiências a partir de blueprints de serviço no cenário remoto
}

Débora Wernke

Mestranda, Universidade Federal de Santa Catarina / deborawernke@gmail.com lattes

Júlio Monteiro Teixeira

Doutor, Universidade Federal de Santa Catarina / julio.teixeira@ufsc.br

Orcid: 0000-0002-9464-2615 / lattes

Enviado: 22/08/2020 // Aceito: 12/12/2020 


\title{
Gestão Visual: mapeando experiências a partir de blueprints de serviço no cenário remoto
}

\begin{abstract}
RESUMO
A Gestão Visual aliada às ferramentas de Design de Serviços mostra-se como uma boa estratégia para a implementação do mapeamento de processos em cenários remotos. O objetivo geral do presente estudo foi apresentar seus conceitos e implementar o service blueprint como uma ferramenta facilitadora para o mapeamento de experiências dos processos da área de Recursos Humanos. Visando proporcionar a melhor interação e prática das ações, foi realizada a pesquisa-ação na empresa Jungle Devs, participando então do mapeamento de toda a jornada do processo de seleção de novos candidatos. O procedimento metodológico foi orientado pelas diretrizes da pesquisa exploratória, partindo de um entendimento sistemático dos processos que ocorriam presencialmente e da análise das atividades exercidas pela empresa. Buscou-se um maior entendimento das atividades dos colaboradores da empresa e da interação deles com os candidatos, identificando assim os pontos problemáticos e a partir destes, o desenvolvimento de recomendações para melhoria e formalização do processo na modalidade remota. A Gestão Visual por meio da ferramenta service blueprint mostrou-se relevante ao alinhamento do time nessa modalidade, além de facilitar o entendimento do processo aos demais colaboradores da empresa. Assim, a implementação do service blueprint como ferramenta visual foi desdobrada à demais processos, e de outras áreas, para que se atingisse a maturidade dos mesmos frente à expansão da empresa.
\end{abstract}

Palavras-chave: gestão visual. Blueprint de serviço. Recursos humanos. 


\title{
Visual Management: mapping experiences from service blueprints in the remote scenario
}

\begin{abstract}
Visual Management combined with Service Design tools is a good strategy for implementing process mapping in remote scenarios. The general objective of this study was to present its concepts and implement the service blueprint as a facilitating tool for mapping the experiences of processes in the Human Resources area. To provide the best interaction and practice of actions, an action research was carried out at the company Jungle Devs, mapping the entire journey of the selection process for new candidates. The methodological procedure was oriented by the guidelines of the exploratory research, starting from a systematic understanding of the processes that took place in person and from the analysis of the activities performed by the company. A greater understanding of the activities of the company's employees and of the interaction with the candidates was sought, thus identifying the problematic points and from these, the development of recommendations for improvement and formalization of the process in the remote mode. Visual Management through the blueprint service tool is known to be relevant to align time in this modality, in addition to facilitating the understanding of the process to the other employees of the company. Thus, an implementation of the service project as a visual tool was deployed to other processes, and from other areas, to reach their maturity in the face of company expansion.
\end{abstract}

Keywords: visual management. Service blueprint. Human resources. 


\title{
Gestión visual: mapeo de experiencias de blueprints de servicio en el escenario remoto
}

\begin{abstract}
RESUMEN
La gestión visual combinada con las herramientas de diseño de servicios es una buena estrategia para implementar el mapeo de procesos en escenarios remotos. El objetivo general de este estudio fue presentar sus conceptos e implementar el anteproyecto de servicio como herramienta facilitadora para mapear las experiencias de procesos en el área de Recursos Humanos. Con el fin de brindar la mejor interacción y práctica de acciones, se realizó investigación acción en la empresa Jungle Devs, participando luego en el mapeo de todo el recorrido del proceso de selección de nuevos candidatos. El procedimiento metodológico se guió por los lineamientos de investigación exploratoria, basados en una comprensión sistemática de los procesos que se llevaron a cabo en persona y el análisis de las actividades realizadas por la empresa. Se buscó un mayor conocimiento de las actividades de los empleados de la empresa y su interacción con los candidatos, identificando así los puntos problemáticos y a partir de éstos, el desarrollo de recomendaciones de mejora y formalización del proceso en modo remoto. La Gestión Visual a través de la herramienta de planos de servicio demostró ser relevante para la alineación del equipo en esta modalidad, además de facilitar la comprensión del proceso al resto de empleados de la empresa. Así, la implementación del blueprint del servicio como herramienta visual se desplegó a otros procesos, y desde otras áreas, para alcanzar su madurez de cara a la expansión de la empresa.
\end{abstract}

Palabras clave: gestión visual. Blueprint de servicio. Recursos humanos. 


\section{INTRODUÇÃO}

O trabalho remoto já antes anunciado como uma tendência a ser adotado pelas empresas, foi antecipado pela epidemia Covid-19 e segue ganhando força na espera pela vacina para o controle da mesma. O retorno às atividades presenciais é adiada a cada mês e o cenário remoto continua obtendo o seu destaque. Mais aplicativos surgem e mais ferramentas são resgatadas para que as operações consigam ser executadas minimizando os efeitos da falta de interação presencial.

O setor de serviços sofreu mais do que os outros pelo fato de nem todos os processos poderem ser realizados de forma remota, já o setor de tecnologia, vem se mostrando resiliente durante o atual cenário mundial. As empresas foram mais facilmente adaptadas ao novo contexto de modalidade de trabalho, visto a utilização diária do próprio produto da área nos processos das empresas. As tecnologias digitais se tornam boas aliadas do trabalho remoto e com ela esta modalidade ganha cada vez mais adesão.

De acordo com a FGV (2020), o número de empresas que pretendem adotar o trabalho remoto deve crescer $30 \%$ após o período de quarentena. Além da segurança em tempos de pandemia, pesquisas apontam que esse modelo de trabalho traz um aumento entre $15 \%$ a $30 \%$ na produtividade do colaborador.

Companhias como Google e Facebook também estenderam o trabalho remoto e outras no entanto viram essa transição como uma oportunidade para adotar a modalidade transformando-a em uma realidade inevitável.

A pesquisa da Talenses Group (2020) mostra como estão as mudanças de quatro frentes distintas nas empresas com o cenário COVID-19: home office, processos seletivos, 
treinamentos e onboarding. O estudo foi apurado entre os dias 27/03/20 e 03/04/20, e respondido por 375 profissionais da área de RH responsáveis por essas temáticas dentro de companhias de diferentes setores (Comércio, Serviços, Indústria e Terceiro Setor).

Em média, apenas 8,8\% das empresas afirmam que nada mudou em relação aos processos seletivos. Por outro lado, $35,2 \%$ das companhias estão realizando os processos de forma remota, 8,8\% mantiveram algumas etapas presenciais, $34,7 \%$ suspenderam todos os processos seletivos, enquanto que $12,5 \%$ estão avaliando caso a caso. Em todos os setores, mais de $70 \%$ acreditam que as mudanças permanecerão integralmente ou parcialmente após o contexto da pandemia (TALENSES GROUP, 2020).

As dificuldades encontradas decorrem da transição forçada e sem planejamento do modelo, no qual todos os processos antes executados em uma sede física da empresa foram transferidos para um ambiente online no trabalho remoto.

Ainda no panorama brasileiro, temos a pesquisa feita pela Robert Half (2020), empresa de recrutamento especializado que entrevistou mais de 800 profissionais no Brasil sobre o trabalho remoto e o futuro do trabalho. Dos entrevistados, $78 \%$ disseram que estão trabalhando em casa e também $86 \%$ gostariam de trabalhar remotamente com mais frequência do que antes da pandemia. Questionados sobre quais medidas as empresas precisam tomar como resultado da pandemia para o novo normal, $91 \%$ esperam que as empresas permitam que os funcionários trabalhem em casa com mais frequência e $72 \%$ esperam realizar menos reuniões e treinamentos presenciais. 
Isso nos revela que todas as funções do escritório podem mudar como resultado de lições que estamos aprendendo enquanto lidamos com a COVID-19. O local de trabalho físico poderá até se tornar a alternativa, enquanto o home office vira a primeira opção (ROBERT HALF, 2020).

Diante dos resultados, nota-se uma inclinação à adoção continuada dos meios remotos após a futura volta às atividades presenciais. Apesar dos benefícios que acompanham a modalidade remota, como a autonomia e liberdade adquiridas nesse processo, a linearidade do trabalho precisa de alguma forma ser também transferida a esse novo ambiente. As funções antes desempenhadas presencialmente passam para essa adaptação digital, ganhando novos meios de serem executadas e capacitando-se para um futuro de trabalho misto pós pandemia.

Com o propósito de implementar uma adaptação para um processo que atenda este contexto remoto e que seja continuado numa futura modalidade mista, foi utilizado como objeto de estudo um processo de seleção para estágio. Posto isso, o objetivo deste estudo é apresentar conceitos de Design e Gestão Visual à área de Recursos Humanos e implementar o service blueprint como uma ferramenta facilitadora no mapeamento de experiências dos processos da mesma.

Para a exploração, foi utilizado como fonte do processo a empresa Jungle Devs, que adaptou seus processos ao contexto remoto. Fundada em fevereiro de 2018 e com sede em Florianópolis, atua na área de desenvolvimento de software, e possui um programa de capacitação para formar profissionais para a área da tecnologia - Programa Academy. Este programa refere-se à modalidade de estágio e servirá de objeto de análise para o artigo. 


\section{GESTÃO VISUAL, DESIGN E PROCESSOS}

Partindo do contexto atual, onde a transição do ambiente físico de trabalho se transportou ao ambiente digital com um menor planejamento, podemos nos voltar ao modo como as adaptações ocorreram e como as operações aconteciam. O que antes era visível ao olhos em uma sala, ou facilmente compartilhado pelo giro de cadeiras entre as mesas, tornouse um pouco mais processual. O trabalho remoto ressalta ainda mais a necessidade de uma comunicação clara e de um fluxo contínuo de conhecimento para permitir a continuidade dos processos, também prezando pela agilidade.

Nesse cenário, a Gestão Visual que antes fazia parte do dia a dia de diversas equipes, transforma-se para sua versão online e contribui para a visualização do trabalho em equipe. À medida que o trabalho se torna mais virtual, a importância de se ter reuniões bem coordenadas aumenta, tanto face a face como em cenários virtuais. Em qualquer tipo de reunião online, manter as pessoas envolvidas é um tremendo desafio que a visualização ativa tenta resolver diretamente (SIBBET, 2013).

A Gestão Visual teve seu destaque através da filosofia Lean, sendo difundida e aplicada, principalmente pelos sistemas de comunicação intuitivos em busca da melhoria contínua na era Toyota. Por vezes foi exemplificado com as linhas de produção e seus painéis de controle nos chãos de fábrica. Apesar de serem anteriormente físicos, com o avanço das metodologias ágeis no setor de tecnologia, as técnicas visuais foram sendo adaptadas ao contexto online. Atualmente podemos contar com uma grande diversidade de aplicativos e sites que dispõem as facilidades de manusear uma ferramenta de Gestão Visual em times remotos. Teixeira (2018) traz o conceito da visualização através de ferramentas 
de Gestão Visual como um eixo condutor de processos de desenvolvimento de projetos.

Segundo o PMBOK $5^{a}$ ed., define-se processo como um conjunto de ações e atividades inter-relacionadas, que são executadas para alcançar um produto, resultado ou serviço predefinido. Cada processo é caracterizado por suas entradas, as ferramentas e as técnicas que podem ser aplicadas e as saídas resultantes.

Gerentes de projeto precisam sempre trabalhar controlando situações, seguindo prazos e processos. Mas isso não significa que eles precisam ser rígidos e agir apenas pelas normas do PMBOK (ECHOS, 2018). A utilização de recursos visuais mostra-se oportuna neste horizonte, o Design Thinking e seu arsenal de ferramentas, vai além das facilitações em reuniões e projetos e foca então em contribuir para uma flexibilização das ferramentas no atual cenário. Ampliando as fronteiras do design, criando uma maior interação entre os profissionais e permitindo a personalização para os diferentes contextos.

O designer enxerga como um problema aquilo que prejudica ou impede a experiência (emocional, cognitiva e estética) e o bem estar na vida das pessoas. Para recuperar tais questões ele organiza o pensamento de forma estrutural e estética, essa é forma de pensar padrão dos designers (TEIXEIRA, 2018).

Assim, o Design Thinking é então a mentalidade e o conjunto de ferramentas que nós designers usamos para entender nossos usuários específicos. Essa abordagem vem para inovar, seja um produto físico ou um produto digital, um serviço, ou outro processo que envolva interações humanas. Assim, é necessário mapear a cultura, os contextos, as experiências pessoais e os processos na vida dos indivíduos para pensar de maneira abdutiva e identificar com eficiência 
os obstáculos para gerar soluções mais assertivas (VIANNA et al., 2012).

Sendo multidisciplinar e com foco no usuário, quando então aplicado ao desenvolvimento de serviços temos então o Design de Serviços. Uma abordagem estruturada que facilita a criação de processos mais úteis e desejáveis para usuários, e ao mesmo tempo, viáveis e eficientes para quem os executa.

Segundo Stickdorn (2014), a abordagem do Design de Serviços se refere ao processo de design e não ao seu resultado final, assim um processo de Design de Serviços pode resultar desde estruturas organizacionais relativamente abstratas, processos operacionais, experiências de serviços e até objetos fisicamente concretos.

Os processos operacionais desempenhados pela área de Recursos Humanos são aqui os serviços que a mesma presta à estrutura organizacional. Fazendo a manutenção da cultura e principalmente recrutando, selecionando e contratando os profissionais que integrarão a empresa. Projetar experiências relacionadas à área de Recursos Humanos requer colocar-se no lugar das pessoas que trabalham na empresa e as pessoas que irão se candidatar a alguma posição.

Ao mapear estas experiências, passamos a pensar nas pessoas, nas dificuldades que encontram, nos seus objetivos, entendendo suas necessidades e aspirações para criar soluções conjuntas com os envolvidos. O mapeamento de experiências permite que você localize a volatilidade transicional dentro de um sistema maior de interações e encontre soluções inovadoras para endereçá-la (KALBACH, 2017). Uma boa jornada deve entregar por meio da cultura e experiências o desenvolvimento pessoal e profissional, bem como o bem estar e os atributos que o usuário necessita enquanto indivíduo. Ao oferecer as melhores experiências, as 
empresas elevam suas possibilidades de retenção, engajamento e posicionamento frente a seus concorrentes.

O Design de Serviços pode por sua vez ajudar a entender e redesenhar os aspectos da experiência dos então colaboradores e possíveis candidatos. Os usuários da área de Recursos Humanos, são também como consumidores, esperam o mesmo tipo de experiências digitais prazerosas, experiências assertivas e contínuas que por vezes são totalmente personalizadas.

Entender as atitudes e comportamentos dos candidatos se torna necessário para um bom processo de seleção. Uma má experiência pode aumentar as taxas de abandono, que correspondem ao número de pessoas que começam, mas não terminam de preencher um formulário de inscrição e também alterar a reputação de uma organização como empregador (Employer Branding).

Assim, o papel do design dentro da área visa criar melhores experiências, a diferença está no tipo de experiência e para quem estamos tentando melhorar esta experiência. Logo, pensar como um designer pode transformar a maneira como desenvolvemos uma comunicação visual, redesenhamos produtos ou serviços, processos ou estratégias.

O design visa uma estruturação dos processos centrada nas pessoas que participam do mesmo, aproximando o conceito da cocriação, fazendo com que o participante se sinta pertencente no decorrer e no resultado do trabalho. Sua visão holística, permite que o processo, seja observado por diferentes ângulos, permitindo assim mais reflexões sobre o mesmo. Além de termos a Gestão Visual apoiando o alinhamento, fomentar equipes multidisciplinares pode promover ainda mais o encontro de pessoas de diferentes áreas e funções ligadas ao processo, favorecendo o olhar sob 
os diversos ângulos e possibilitando assim um detalhamento maior.

\section{PROCEDIMENTOS METODOLÓGICOS}

Para conduzir o estudo foi selecionado um método de caráter exploratório. A natureza dos problemas tratados no campo do Design frequentemente exige do pesquisador uma maior aproximação com o mercado para possibilitar sua compreensão. Afinal, estamos tratando de uma disciplina dentro do campo de conhecimento das Ciências Sociais "Aplicadas" (SANTOS, 2018).

No contexto de organizações, a pesquisa-ação é apropriada quando a pesquisa procura descrever as operações e desenvolvimentos de ações ao longo do tempo para um grupo, comunidade ou gerenciamento específico (COGHLAN E BRANNICK, 2001). Além disso, a pesquisa-ação procura entender como um membro de um determinado grupo executa uma ação, como e por que essa ação pode mudar ou melhorar a funcionamento de um sistema e como o processo de mudança ou melhoria permite gerar de aprendizagem (COGHLAN E BRANNICK, 2001).

Para a aplicação da pesquisa, a empresa Jungle Devs a partir do seu processo seletivo para estagiários será o objeto de estudo. A empresa pertence ao setor de tecnologia e atua na área de desenvolvimento de produtos digitais, possuindo além das contratações no modelo celetista, o Programa Academy. Este programa refere-se à modalidade de estágio, e está destinado a capacitação de novos profissionais para a área da tecnologia.

O programa tem duração de um ano, e é focado para os alunos de universidades próximas que estejam no início de 
sua carreira. A cada trimestre um novo desafio, focado no aprendizado da teoria na prática, passando pela participação em projetos reais da companhia. Hoje os participantes contam com especializações para Desenvolvimento Front-end, Desenvolvimento Back-end, Desenvolvimento iOS, Desenvolvimento Android e Design UI/UX.

A Jungle Devs tem a cultura do aprendizado como elemento principal no seu modo de conduzir a organização. Seu objetivo é difundir sempre que possível sua cultura de ensino de tecnologia, seja para as pessoas que já fazem parte da organização ou para novos e/ou futuros membros.

A cultura revela a conduta de um determinado grupo, sendo para as organizações como normativas a serem seguidas, que podem ser formalizadas e escritas como missão, visão e valores e outras de maneira mais informal, percebidas pelos indivíduos que a vivem e percebem os seus efeitos. Para Schein (1989), um dos autores reconhecidos quando se fala sobre a cultura organizacional, o conceito de cultura organizacional é:

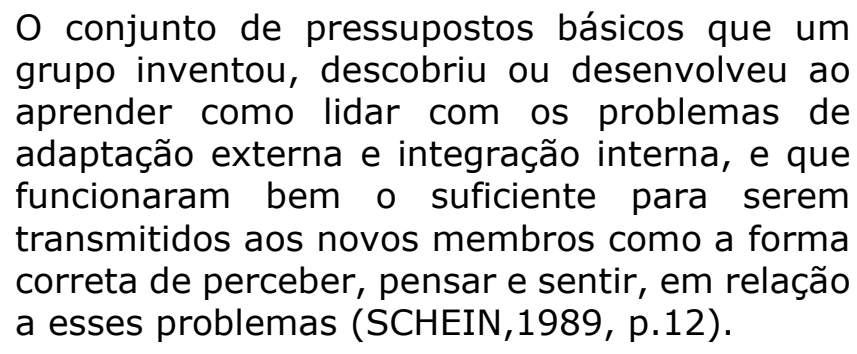

Essa cultura de aprendizado também se estende aos processos de seleção para o Programa Academy. Nele, os participantes podem ter acesso a plataforma de desafios, desenvolvida internamente, para o fomento do ensino de base. Mesmo que o candidato não avance para as próximas fases, pode ter acesso ao conteúdo e fazer os exercícios para uma possível aplicação futura. Enquanto cultura, o desafio é estender cada vez mais as experiências de aprendizado 
internas, através de processos como os de mentoria, aos futuros candidatos.

Com a adoção do software de gerenciamento de candidatos, Workable, veio a necessidade da equipe de Pessoas e Cultura (equipe similar a Recursos Humanos) de rever o atual processo e melhorar as experiências vividas tanto pelos possíveis novos membros quanto para a equipe interna que executa as etapas. Além de identificar as adaptações necessárias ao modelo remoto para todos os envolvidos no processo.

Reconhecido então, como um objeto adequado para o estudo de ferramentas do design aplicadas a processos de Recursos Humanos.

\title{
3.1 Blueprint de Serviços
}

Shostack (1984), propôs através de seu artigo o Service Blueprint, uma ferramenta que entregava uma nova maneira de estruturar e visualizar os serviços, mais organizada e sistemática.

\begin{abstract}
A raiz da maioria dos problemas do serviço é, de fato, a falta de um design sistemático e controle. O uso de um diagrama pode ajudar um desenvolvedor do serviço não só a identificar os problemas antecipadamente, mas também a ver - potencial para novas oportunidades de mercado (SHOSTACK,1989 apud KALBACH, 2017, p.229).
\end{abstract}

O Blueprint de Serviços é uma ferramenta adaptável, cada profissional pode usá-la da forma que melhor se adequar ao contexto, adicionando ou retirando as seções. Torna-se importante encontrar um equilíbrio entre a estrutura básica e o contexto a ser aplicado para que se possa visualizar as jornadas de maneira assertiva, sem informações 
desnecessárias que dificultem o mapeamento e a visualização do todo.

Como ferramenta, este trabalho utilizou a Blueprint de Serviços, para que fosse feito o mapeamento do processo seletivo bem como o mapeamento das experiências envolvidas no processo. A ferramenta é um dos tipos de diagrama de alinhamento de valor, que se apresenta de forma cronológica e mostra ambos os lados da criação de valor em uma única visualização. Sua aplicação permite figurar todas as fases da jornada do cliente, suas ações e reações, e também as fases que acontecem dentro da sua empresa.

Mapear um processo, além de ser uma boa maneira de entender todas as etapas necessárias para concluir seu fluxo de trabalho e manter todos os envolvidos alinhados, faz parte da tarefa de uma organização que busca uma escalabilidade sustentável.

Geralmente, o mapeamento de processos é feito para estabelecer padrões ou procedimentos de execução da empresa. Neste sentido, o mapeamento de processos vem ao encontro da identificação dos principais passos e decisões em um fluxo de trabalho de rotina de forma visual. Também controla o fluxo de informações, materiais e documentos envolvidos no processo e esclarece tarefas, decisões e ações que são necessárias em determinados pontos no tempo (SANTOS et al., 2015).

No entanto, o mapeamento dos processos por meio de abordagens do design vai além de organizar as etapas e entender suas relações para otimizar o processo, busca-se todas as experiências que serão despertadas a cada etapa para cada um dos envolvidos. Dessa forma, o pensamento centrado no usuário e a capacidade de ter empatia, irão ser a base para a execução do alinhamento de cultura e valores ao processo. 
Além de trazer o benefício de tornar o processo cada vez mais visual, através do design de informação, segundo Shedroff (2000) pode-se organizar e apresentar dados, transformando-os em informação com sentido e valor, oferecendo uma estrutura necessária para que elas expressem suas capacidades.

Um bom design de informação reduz o cansaço e erros no processamento de informações, acelera o trabalho e faz com que a informação seja atrativa e adequada à situação em que se apresenta (QUINTÃO; TRISKA, 2013).

\subsection{Apresentação dos conceitos de design e da ferramenta blueprint de serviço}

Para dar início, a fase exploratória delimitou apenas ao processo seletivo na modalidade de estágio para o desenvolvimento deste trabalho, não se estendendo ao mapeamento do processo seletivo na modalidade celetista. $\mathrm{Na}$ sequência buscou-se o planejamento colaborativo, identificando os membros da equipe e dos grupos interessados na pesquisa para então dar sequência ao mapeamento do processo seletivo. Cabe ressaltar que é importante que as pessoas envolvidas no mapeamento sejam familiarizadas com o processo.

A equipe composta para mapeamento do processo de seleção contém integrantes que possuem graduações em áreas diversas tais como Engenharia de Automação, Engenharia de Produção, Psicologia e Design. A fim de apresentar os conceitos que seriam utilizados para esta tarefa, foi feito uma triagem sobre princípios que regem o design, quais suas aplicações, como ele se insere na área de Recursos Humanos, e quais ferramentas poderiam ser 
utilizadas. Após a compilação desse material foi apresentado à equipe com a finalidade de nivelar o conhecimento sobre.

\subsection{Mapeamento de Persona}

A partir do entendimento sobre as ferramentas advindas do design, iniciou-se o trabalho colaborativo para a construção da persona vinculada a modalidade de estágio bem como suas dores, dia a dia e pontos de contato com a marca.

Personas são perfis fictícios, muitas vezes desenvolvidos como uma maneira de representar um grupo específico de pessoas com base em seus interesses comuns. Podem ser construídas como uma atividade de grupo nos workshops. Isso facilita as discussões acerca de segmentos específicos de clientes/usuários do serviço (STICKDORN, 2014, p.181).

Os envolvidos com o processo poderam trazer suas perspectivas de acordo com os dados internos vinculados ao Programa Academy para o workshop de empatia. 
Figura 1. Estudo sobre Personas

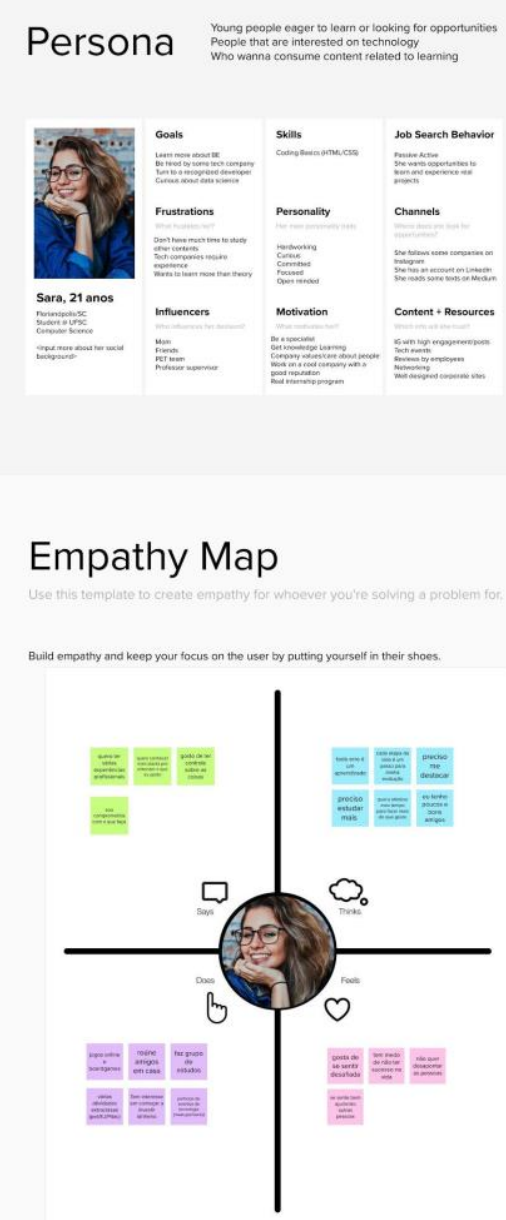

To-be Scenario Map

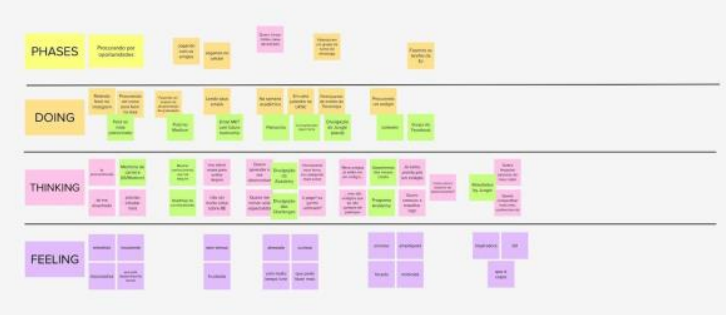

Journey
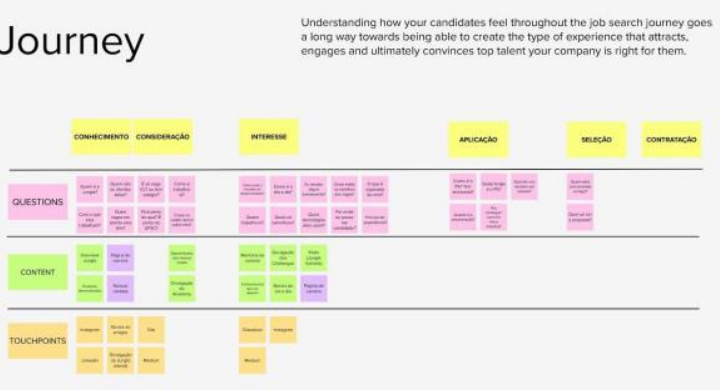

Fonte: Jungle Devs (2020).

Ao final do workshop, validou-se as informações com mais pessoas para que então se desse continuidade às etapas.

\subsection{Escolha da ferramenta virtual}

Apesar de termos a possibilidade da utilização das ferramentas digitais para facilitar o trabalho remoto, algumas equipes podem encontrar algumas barreiras técnicas. As aplicações são por vezes orientadas a algum tipo de software específico, não podendo ser em sua totalidade personalizadas e por outro lado requerem certo domínio para que se possa 
utilizá-las.

Pensando em trazer uma experiência colaborativa em tempo real para esta tarefa, utilizou-se o site Mural.ly, que é uma plataforma de colaboração visual online. Permite escrever em notas adesivas digitais, simulando os físicos Postits, permitindo sua movimentação ou troca de cor e tamanho. Também possui um cronômetro integrado que pode fazer a contagem regressiva para as sessões criativas.

Apesar do Mural já possuir um template para blueprint de serviço, o template disponibilizado segue a estrutura proposta pelo Practical Service Design que corresponde a uma aplicação mais profunda de serviço. Portanto, para este mapeamento foi utilizado um blueprint personalizado, feito através dos elementos disponibilizados no site, descritos na etapa seguinte.

\subsection{Personalização da blueprint}

Com o propósito de adequar a blueprint de serviços ao mapeamento de um processo seletivo, buscou-se primeiramente entender quais seriam as raias que precisariam estar na estrutura da ferramenta. A partir da revisão dos documentos do processo identificou-se as seções descritas na imagem abaixo. 
Figura 2. Estrutura da blueprint do processo seletivo

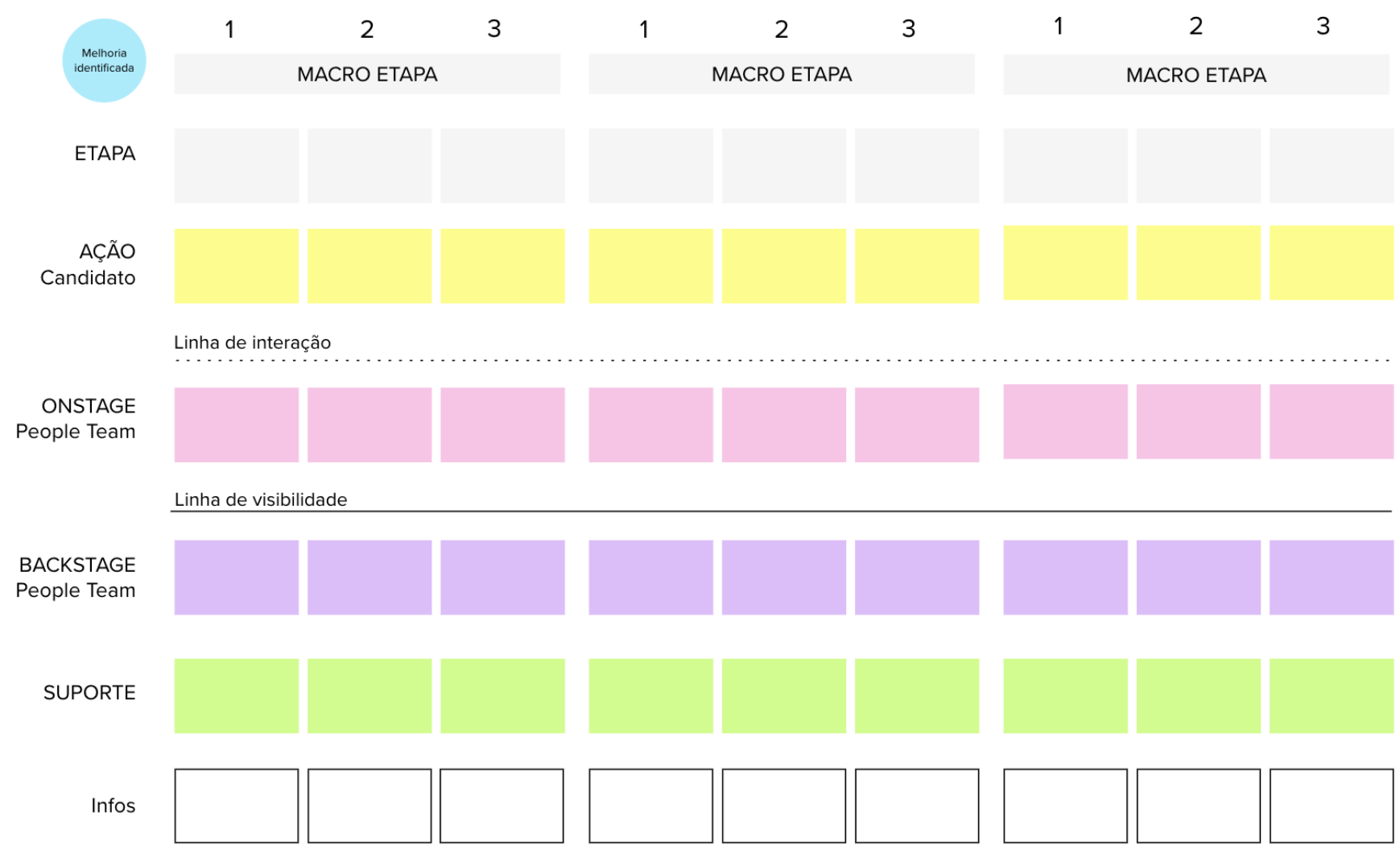

Fonte: Jungle Devs (2020).

Para que fosse possível essa personalização, procuramos entender os pontos que precisavam ser evidenciados, bem como os atores e pessoas de suporte ao processo em questão:

- Macro etapas: identificadas pelas barras cinza-claro, procurou-se diferenciar as mesmas para que após o mapeamento fosse possível identificar as ações de melhoria a serem feitas em um diagrama de valor $\mathrm{x}$ esforço.

- Etapas: identificadas pelas notas cinza-claro, estão na posição das evidências físicas, aqui adaptadas para o escopo do processo. 
- Ação Candidato: identificadas pelas notas amarelas, são todas as interações que o candidato têm com as etapas do processo.

- Onstage People Team: identificadas pelas notas rosas, são todas as interações que a equipe têm com os candidatos.

- Backstage People Team: identificadas pelas notas lilás, são todas as ações que acontecem internamente na equipe, ou seja, os candidatos não são atores pertencentes a ação.

- Suporte: identificadas pelas notas verdes, são todas as ações que acontecem entre a equipe e atores de suporte, tais como pessoas de outras equipes ou fornecedores externos de serviços.

- Infos: identificados pelas notas brancas, são informações complementares que devem acompanhar os artefatos e/ou templates vinculados à etapa.

- Melhorias: identificados pelas notas circulares em azul, são as melhorias identificadas no decorrer do mapeamento.

A intenção deste mapeamento inicial é criar uma versão de baixa fidelidade, e assim que as etapas forem definidas, redesenhá-lo em um outra plataforma a fim de se tornar a documentação oficial do processo.

Para este trabalho em especial, fora escolhido o processo seletivo para estágio (Programa Academy) que já possuía uma estrutura previamente documentada em formato .doc, a qual fica a disposição de todos na equipe. A partir da identificação das etapas e macro-etapas iniciou-se o preenchimento da blueprint nas zonas indicadas por cinza. 


\section{RESULTADOS}

A partir de cada etapa, foram detalhadas as ações correspondentes em cada uma das raias em sentido vertical. As raias que não participavam ativamente da etapa eram deixadas em branco, seguindo assim até o final do processo. Notou-se que a utilização de uma ferramenta visual permitiu que fossem identificadas etapas antes não descritas, conduzindo a equipe a um melhor entendimento do fluxo.

Previamente era utilizada a ferramenta SIPOC, que atua na melhoria de processos pontuando as entradas e saídas em forma de tabela. Esta técnica tem como objetivo melhorar a visualização da sequência de processos por todos os membros da empresa diretamente ligados a estes (ANDRADE et al., 2012). No entanto, esta ferramenta não apresentava a visualização do encadeamento das etapas feitas pelos candidatos, desconsiderando as experiências por parte dos mesmos. Impossibilitando assim, o entendimento do fluxo total do processo e bem como a compreensão das necessidades reais dos participantes da seleção.

A visualização do todo, favorecida pela blueprint, fomentou um olhar holístico por parte de todos os envolvidos. Sendo assim, adicionou-se tais etapas entre as seções equivalentes, preenchendo-as com as ações no sentido topdown. 
Figura 3. Blueprint do processo seletivo feito no Mural.ly

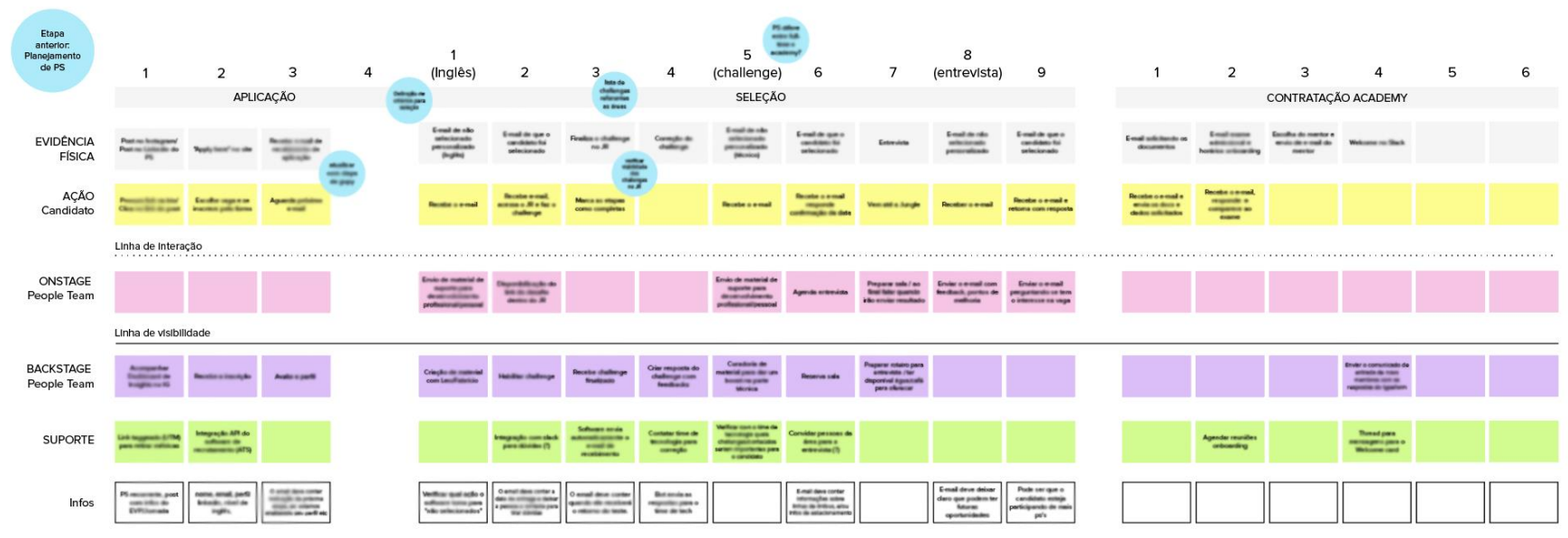

Fonte: Jungle Devs (2020).

Ao final do mapeamento através da blueprint, seguiu-se com a coleta de feedbacks de pessoas que recém tinham passado pelo processo, a fim de adicionar possíveis novas melhorias ainda não identificadas pela equipe de trabalho para a modalidade remota.

Além das melhorias, foram identificadas as etapas que não estavam anteriormente descritas na documentação feita com o uso do SIPOC, como as etapas que foram adaptadas ao contexto online e toda a sequência de contato que os candidatos têm com as etapas do processo. A partir de um melhor entendimento das personas e posteriormente do uso do service blueprint, foi possível identificar quais etapas não estavam entregando uma experiência alinhada à cultura da empresa e assim foram elencadas para atualizações no processo. Este resultado reforçou na prática como o foco do design de serviços organiza as experiências indo além do simples sequenciamento de etapas, entregando uma visualização facilitada e também valor a todos os atores participantes do processo.

Importante ressaltar que o mapeamento não servirá apenas para que a experiência do candidato seja alinhada com 
a proposta do processo em questão, mas também que a experiência da equipe que executa 0 processo seja conveniente. Um dos maiores ganhos deste mapeamento foi a sequência de ações para o exame admissional, necessário para a macro etapa de contratação. Esta, anteriormente era apresentada apenas como uma etapa chamada "Exame Admissional", mas na realidade onerava quatro etapas com envio sequenciado de informações até a consulta ser definitivamente marcada. Com a identificação deste gargalo, houve a oportunidade da otimização do processo, reconfigurando 0 agendamento, tornando-o mais independente e menos maçante para a equipe e também ao candidato.

As experiências ruins dos candidatos geralmente se devem a uma deficiência organizacional interna ou a falta de uma informação na comunicação que é enviada. Ao contrário do SIPOC que não fornecia uma jornada tão clara à equipe, o service blueprint conseguiu expor um panorama visual oferecendo um mapa de dependências e permitindo deste modo que a experiência ruim fosse revisada.

A partir das informações verificadas em cada etapa e das supostas dúvidas por parte dos candidatos na etapa de Mapeamento de Personas foram listados os artefatos que integrariam as etapas, tais como templates de e-mail, apresentações e diretrizes para as equipes que interagem com as etapas de feedback.

Ao final o processo, já com os itens de melhoria, foi posto para iteração dentro da plataforma de gerenciamento de candidatos (Workable), e assim pode-se ir ajustando as etapas e artefatos para que o processo pudesse rodar de maneira mais escalar. 


\section{CONSIDERAÇÕES FINAIS}

Apesar deste ciclo de uso do blueprint ter encerrado, devese ter como próximos passos a contínua iteração do processo. Voltando-se sempre ao escopo para que a partir dos feedbacks recebidos, seja possível refiná-lo com o tempo.

Seguir as etapas anteriormente descritas ofereceu a toda a equipe além de uma prática com a ferramenta, uma visão geral e linear do processo em evidência. A visualização global do processo propaga a ótica do design, favorecendo a experiência do candidato. Os envolvidos no processo passam a enxergar o processo como um todo, e deixam de apenas se preocuparem com suas etapas específicas.

O uso da ferramenta interativa - Mural.ly - garantiu que todos pudessem compartilhar suas ideias em tempo real, permitindo que mais revisões de processo como essas possam ser feitas no modelo remoto. Essa Gestão Visual do processo, atrelada aos princípios de design, pode organizar a informação coletada e planejar sua apresentação final.

O processo centrado no estudo dos comportamentos do candidato, aproximou e engajou o time a exercitar cada vez mais as noções de empatia que o Design Thinking propõe. 0 blueprint de serviços se mostrou uma ferramenta visual que além de aproximar a equipe para identificação de gargalos e melhorias, torna a compreensão dos processos internos com uma abordagem cronológica, melhorando o entendimento das etapas sequenciais e das ações que necessitam ser tomadas. 


\section{REFERÊNCIAS}

ANDRADE, Gabriela Exupery Virga de et al. Análise da aplicação conjunta das técnicas SIPOC, Fluxograma e FTA em uma empresa de médio porte. XXXII Encontro Nacional de Engenharia de Produção. Bento Gonçalves/RS. Out. 2012. Disponível em: http://www.abepro.org.br/biblioteca/ENEGEP2012_TN_WIC_157_9 20_20681.pdf. Acesso em: 22 dez. 2020.

DIÁRIO DO COMÉRCIO. Home office será mantido por mais de $\mathbf{7 0 \%}$ das empresas no pós-crise. Disponível em: https://dcomercio.com.br/categoria/gestao/home-office-seramantido-por-mais-de-70-das-empresas-no-pos-crise. Acesso em 1 ago. 2020.

ECHOS. Gestão de projetos: como o design thinking pode ajudar? Disponível em: https://escoladesignthinking.echos.cc/blog/2018/03/gestao-deprojetos-como-o-design-thinking-pode-ajudar/. Acesso em 1 ago. 2020.

FINANCIAL TIMES. Why HR chiefs must rethink talent management after Covid-19. Disponível em: https://www.ft.com/content/71ad5416-a4a4-11ea-81ac4854aed294e5. Acesso em: 31 jul. 2020.

$\mathrm{KALBACH}$, J. Mapeamento de Experiências, Um guia para criar valor por meio de jornadas, blueprints e diagramas. Rio de Janeiro: Alta Books Editora. 2017

SANTOS, Lucas Almeida dos et al. Mapeamento de processos: um estudo no ramo de serviços. Iberoamerican Journal Of Industrial Engineering. Florianópolis, p. 108-128. jan. 2015.

PMI. Um guia do conhecimento em gerenciamento de projetos (guia PMBOK®). Project Management Institute, 5. ed, Saraiva, 2013.

QUINTÃO, Fernanda S.; TRISKA, Ricardo. Design de informação em interfaces digitais: origens, definições e fundamentos. Revista Brasileira de Design da Informação, São Paulo, v. 10, n. 2, p. 105-118, 2013.

ROBERT HALF. Home office agrada a maioria: como será a volta ao escritório? Disponível em: https://www.roberthalf.com.br/blog/tendencias/home-officeagrada-maioria-como-sera-volta-ao-escritorio. Acesso em 2 ago. 2020.

SANTOS, Aguinaldo dos. Seleção do método de pesquisa: guia para pós-graduando em design e áreas afins / Aguinaldo dos Santos. Curitiba, PR : Editora Insight, 2018. 230 p.

SHEDROFF, N. Information interaction design: a unified field theory of design. In: JACOBSON, Robert (ed.). Information design. Cambridge (MA): The MIT Press, 2000.

SCHEIN, Edgar H. Organizational culture and leadership. San Francisco, Jossey Bass, 1989. 
SIBBET, D. Reuniões Visuais: como gráficos, lembretes autoadesivos e mapeamento de ideias podem transformar a produtividade de um grupo. Rio de Janeiro: Alta Books, 2013.

STICKDORN, Marc; SCHNEIDER, Jakob (Org.). Isto é Design Thinking de Serviços. Porto Alegre: Bookman, 2014.

TALENSES. Pesquisa | Processos de admissão, onboarding e treinamento no cenário COVID-19. Disponível em: https://talenses.com/pt/publicacoes/news-that-matter/pesquisaprocessos-de-admissao-onboarding-e-treinamento-no-cenariocovid-19. Acesso em 1 ago. 2020.

THIOLLENT, M. Metodologia da Pesquisa-Ação. 18a ed. São Paulo: Cortez, 2011.

VIANNA, $M$. et al. Design Thinking: Inovação em negócios. Rio de Janeiro: MJV Press, 2012. $161 \mathrm{p}$. 